\title{
Effects of an Alveolar Recruitment Maneuver During Lung Protective Ventilation on Postoperative Pulmonary Complications in Elderly Patients Undergoing Laparoscopy
}

This article was published in the following Dove Press journal:

Clinical Interventions in Aging

Youn Yi Jo

Kyung Cheon Lee

Young Jin Chang

Wol Seon Jung

Jongchul Park

Hyun Jeong Kwak (iD)

Department of Anesthesiology and Pain Medicine, Gachon University College of Medicine, Gil Hospital, Incheon, Republic of Korea
Correspondence: Hyun Jeong Kwak Email hyun6I5@gilhospital.com
Purpose: Controversy remains over whether alveolar recruitment maneuvers (ARMs) can reduce postoperative pulmonary complications. We hypothesized that performing an ARM in addition to lung protective ventilation (LPV) could improve intraoperative arterial oxygenation and postoperative pulmonary complications (PPCs) in elderly patients undergoing laparoscopy in the Trendelenburg position.

Patients and Methods: Sixty-two patients (aged 65-85) scheduled for laparoscopic low anterior resection were randomized to receive LPV only (LPV group, $\mathrm{n}=32$ ) or LPV with an ARM (ARM group, $\mathrm{n}=30$ ). LPV was set to a tidal volume of $6 \mathrm{~mL} / \mathrm{kg}$ with a positive end expiratory pressure (PEEP) of $5 \mathrm{cmH}_{2} \mathrm{O}$. The ARM was performed by serially increasing the PEEP to $10 \mathrm{cmH}_{2} \mathrm{O}$ for 3 breaths, $15 \mathrm{cmH}_{2} \mathrm{O}$ for 3 breaths, then $20 \mathrm{cmH}_{2} \mathrm{O}$ for 10 breaths, both immediately before and after abdominal insufflation. The primary end-point was the frequency of PPCs such as desaturation $\left(\mathrm{SpO}_{2}<90 \%\right)$, atelectasis, and pneumonia. Secondary end-points were changes in intraoperative respiratory and gas exchange parameters and hemodynamic variables.

Results: One patient in the LPV group experienced desaturation on the first postoperative day. The frequency of chest X-ray abnormalities such as atelectasis or pleural effusion was comparable between groups $(6(19 \%)$ and $5(17 \%)$ patients, respectively, $\mathrm{P}=$ 0.676). Changes in other respiratory, gas exchange and hemodynamic parameters over time were not significantly different between the groups. However, vasopressor requirements during surgery were higher in the ARM than the LPV group (9 (30\%) and $2(6 \%)$ patients, respectively, $\mathrm{P}=0.014$ ).

Conclusion: This study suggests that performing an ARM during LPV may not improve postoperative respiratory outcomes and intraoperative oxygenation compared to LPV alone in geriatric patients undergoing laparoscopy in the Trendelenburg position. In addition, since the ARM could cause a significant deterioration in hemodynamic parameters, applying ARM to elderly patients should be carefully considered.

Keywords: alveolar recruitment maneuver, geriatric, lung protective ventilation, pneumoperitoneum

\section{Introduction}

For patients undergoing major abdominal surgery under general anesthesia, a laparoscopic as opposed to an open approach is associated with increased life expectancy due to more rapid recovery. ${ }^{1}$ Despite the development of 
minimally invasive surgical procedures, age-related changes in lung physiology such as the deterioration in respiratory system compliance, as well as a diminished response to hypoxemia and a decrease in other protective airway reflexes, still increase the chance of developing postoperative pulmonary complications (PPCs). ${ }^{2}$ PPCs are associated with a prolonged hospital stay and the need for intensive care, leading to an increase in health care costs. ${ }^{3}$ Also, the closing volume tends to exceed functional residual capacity with aging, ${ }^{4}$ and this change leads to abnormal intraoperative gas exchange and postoperative atelectasis. ${ }^{2}$ Carbon dioxide $\left(\mathrm{CO}_{2}\right)$ pneumoperitoneum during laparoscopy in the Trendelenburg position decreases lung volume and lung compliance, ${ }^{5}$ and respiratory compliance might not completely recover even after the cessation of pneumoperitoneum. ${ }^{6}$

Most lung protective ventilation (LPV) strategies to minimize ventilator-induced lung injury are based upon low tidal volume ventilation and permissive hypercapnia. $^{7}$ The use of alveolar recruitment maneuvers (ARMs) for recruiting collapsed alveoli is a ventilation strategy involving transient or staircase elevations in transpulmonary pressure. A recent meta-analysis of 12 trials involving a total of 2756 anesthetized patients reported that using an ARM in combination with LPV reduced the incidence of PPCs in non-obese patients. ${ }^{8}$ Another study showed that the combination of an ARM and positive endexpiratory pressure (PEEP) significantly improved oxygenation and reduced atelectasis, but PEEP or an ARM alone did not improve these parameters in obese patients. ${ }^{9}$

Despite the clinical importance of perioperative respiratory care in elderly patients, there is little literature examining the reduction of PPCs after laparoscopic surgery in elderly patients. We hypothesized that performing an ARM in addition to LPV might improve intraoperative oxygenation and respiratory parameters, and thus would lead to reducing the PPCs. Therefore, the aim of this prospective randomized study was to evaluate the effect of ARM on PPCs as well as intraoperative oxygenation, respiratory mechanics, and hemodynamic variables in elderly patients undergoing laparoscopic surgery.

\section{Methods}

\section{Patients}

This study was approved by the Gachon University Gil Hospital Institutional Review Board (Ref: GBIRB2017-
270) and registered at ClinicalTrials.gov (NCT 03331471). Prior written informed consent was obtained from all eligible participants. This study is conducted in accordance with the Declaration of Helsinki. In this prospective observational study, 64 patients scheduled for elective laparoscopic low anterior resection for colorectal cancer were included. This study included patients aged 65-85 with an ASA physical status of 1 or 2, and excluded patients with active infectious lung disease, moderate to severe obstructive or restrictive lung disease on pulmonary function test, symptomatic cardiovascular disease besides proper medication, and cerebrovascular disease with neurologic sequelae. Participants were randomly assigned to the lung protective ventilation group ( $\mathrm{LPV}$ group; $\mathrm{N}=32$ ) or the alveolar recruitment maneuver group (ARM group; $\mathrm{N}=32$ ) using the randomization function in Excel 2013 (Microsoft office, Redmond, WA) without stratification.

\section{Anesthesia and Study Setting}

Patients were not premedicated with any sedatives or analgesics. In the operating room, routine anesthesia monitors such as a pulse oximeter, a non-invasive blood pressure monitor, and an electrocardiograph were employed. Neuromuscular blockade was monitored using E-NMT module (GE Healthcare, Helsinki, Finland) to obtain a train-of-four (TOF) ratio, which was measured every $15 \mathrm{~s}$. For the induction of anesthesia, lidocaine $(1 \mathrm{mg} /$ $\mathrm{kg}$ ), remifentanil $(0.5-1.0 \mu \mathrm{g} / \mathrm{kg})$, propofol $(1-2 \mathrm{mg} / \mathrm{kg})$, and rocuronium $(0.8 \mathrm{mg} / \mathrm{kg})$ were administered. For the maintenance of anesthesia, the concentration of sevoflurane used (1.5-2 vol\%) was adjusted guided by the bispectral index score aiming to maintain between 40 and 60 . To enable blood sampling and continuous blood pressure monitoring, a 22-G radial arterial catheter was inserted after the induction of anesthesia. Target TOF ratio was under 0.3 during anesthesia and ARM. During emergence, extubation was considered after recover the TOF ratio over 0.9. The mechanical ventilator for LPV was set in volumecontrolled mode based on a tidal volume of $6 \mathrm{~mL} / \mathrm{kg}$ of ideal body weight (defined in $\mathrm{kg}$ as $0.919 \times$ (height in $\mathrm{cm}$ $-152.4)+45.5$ for women, or +50 for men), an inspiratory to expiratory (I/E) ratio of 1:2, a PEEP of $5 \mathrm{cmH}_{2} \mathrm{O}$, and an inspired oxygen fraction $\left(\mathrm{FiO}_{2}\right)$ of 0.5 . The level of PEEP was determined based on the previous study. ${ }^{10}$ The respiratory rate was adjusted to maintain an end-tidal carbon dioxide tension $\left(\mathrm{ETCO}_{2}\right)$ between 35 and 45 $\mathrm{mmHg}$. For the LPV group, the initial ventilator settings were maintained throughout the surgery. For the ARM 
group, an additional ARM was performed during LPV immediately before and after abdominal insufflation with $\mathrm{CO}_{2}$ gas. This ARM serially increased the PEEP from the initial ventilator settings to $10 \mathrm{cmH}_{2} \mathrm{O}$ for 3 breaths, 15 $\mathrm{cmH}_{2} \mathrm{O}$ for 3 breaths, then $20 \mathrm{cmH}_{2} \mathrm{O}$ for 3 breaths. The peak airway pressure (Ppeak) during ARM was limited to $40 \mathrm{cmH}_{2} \mathrm{O}$. The insufflation gas pressure for pneumoperitoneum was limited to $12 \mathrm{mmHg}$. After gas insufflation, the patient was moved from the supine position into the $30^{\circ}$ Trendelenburg position.

When mean arterial pressure (MAP) decreased below $80 \%$ of the baseline value during surgery, either $50 \mu \mathrm{g}$ phenylephrine or $5 \mathrm{mg}$ ephedrine was used, depending on the heart rate (HR). The requirement of vasopressors in each patient was recorded. At $10 \mathrm{~min}$ after anesthesia induction, $1 \mathrm{~min}$ after the induction of pneumoperitoneum, $60 \mathrm{~min}$ after the induction of pneumoperitoneum, the end of pneumoperitoneum, and the end of the operation, respiratory parameters including $\mathrm{ETCO}_{2}$ and Ppeak and plateau airway pressure (Pplat) were recorded, and arterial blood gas analysis was performed. Alveolar oxygen tension was calculated using the following equation: Alveolar oxygen tension $=\mathrm{FiO}_{2} \times(760-47 \mathrm{mmHg})-\left(\mathrm{PaCO}_{2} / 0.8\right)$, and the alveolar to arterial oxygen tension gradient $\left(\mathrm{AaDO}_{2}\right)$ was estimated. Alveolar dead space fraction $(\mathrm{Vd} / \mathrm{Vt})$ was calculated using the following equation: $\mathrm{Vd} /$ $\mathrm{Vt}=1.135 \times\left(\mathrm{PaCO}_{2}-\mathrm{ETCO}_{2}\right) /\left(\mathrm{PaCO}_{2}-0.005\right) \times 100 .{ }^{11}$ Dynamic and static lung compliance (Cdyn and Cstat) were calculated using the following equations: Cdyn = tidal volume/(Ppeak - PEEP); Cstat = tidal volume/ (Pplat - PEEP).

If the patient subjectively complained of dyspnea in the ward within 48 hours after the operation, oxygen saturation was measured. All enrolled patients were enrolled for chest X-ray on the first and second post-operative day. PPCs are defined as the presence of at least one of the following: the presence of desaturation (defined as $\mathrm{SpO}_{2}$ $<90 \%$ in room air), clinical signs and symptoms including respiratory infection, respiratory failure and bronchospasm, and abnormal chest X-ray findings including pleural effusion, atelectasis, pneumothorax, aspiration pneumonitis and pulmonary edema. ${ }^{12}$

\section{Statistical Analysis}

The primary outcome was the incidence of PPCs in the first 2 days of the postoperative period. Sample size was calculated based on a previous study ${ }^{13}$ comparing the prevalence of PPCs after anesthetic protocols with and without an ARM
( $47 \%$ and $14 \%$, respectively). In that study, 29 patients were required in each group to achieve an $\alpha$-error probability of 0.05 and a power of $80 \%$; we, therefore, recruited 32 patients to each group, considering possible drop-outs.

SPSS version 19.0 (SPSS Inc., Chicago, IL, USA) was used for data analysis. Results were presented as mean \pm standard deviation (SD) or as the number of patients (\%). The normality of variable distribution was tested using the Kolmogorov-Smirnov test. Continuous variables were compared using the independent $t$-test or the MannWhitney $U$-test, and categorical variables were compared using Fisher's exact test or the chi square test as appropriate. Changes in hemodynamic and respiratory variables were analyzed using a 2-way repeated measures ANOVA with two factors (group and time). $P$ values $<0.05$ were considered to be statistically significant.

\section{Results}

\section{Participants and Preoperative Data}

A total of 64 patients were enrolled in this prospective study; two patients in the ARM group were excluded from analysis due to a change in the surgical plan (Figure 1). Patient characteristics and preoperative respiratory variables (arterial blood gas analysis and pulmonary function test results) were comparable between the groups (Table 1).

\section{Intraoperative Data}

Intraoperative data including operation time, anesthesia time, and pneumoperitoneum time were comparable between the groups (Table 2).

\section{Intraoperative Changes of Gas Exchange and Dead Space Fraction}

The changes in $\mathrm{PaO}_{2}, \mathrm{PaCO}_{2}, \mathrm{AaDO}_{2}$, and $\mathrm{Vd} / \mathrm{Vt}$ during surgery are illustrated in Figure 2. There were no significant differences between the groups in the changes in $\mathrm{PaO}_{2}, \mathrm{PaCO}_{2}, \mathrm{AaDO}_{2}$, and $\mathrm{Vd} / \mathrm{Vt}$ over time (group-bytime interaction $\mathrm{P}=0.615,0.818,0.624$, and 0.440 , respectively). There were also no significant differences between the groups in the changes in intraoperative respiratory mechanics over time (group-by-time interactions for Ppeak, Pplat, Cdyn, and Cstat: $\mathrm{P}=0.988$, $0.897,0.653$, and 0.275 , respectively, data not shown).

\section{Intraoperative Hemodynamic Changes}

The changes in hemodynamics are illustrated in Figure 3. The differences between the groups in the changes in MAP 


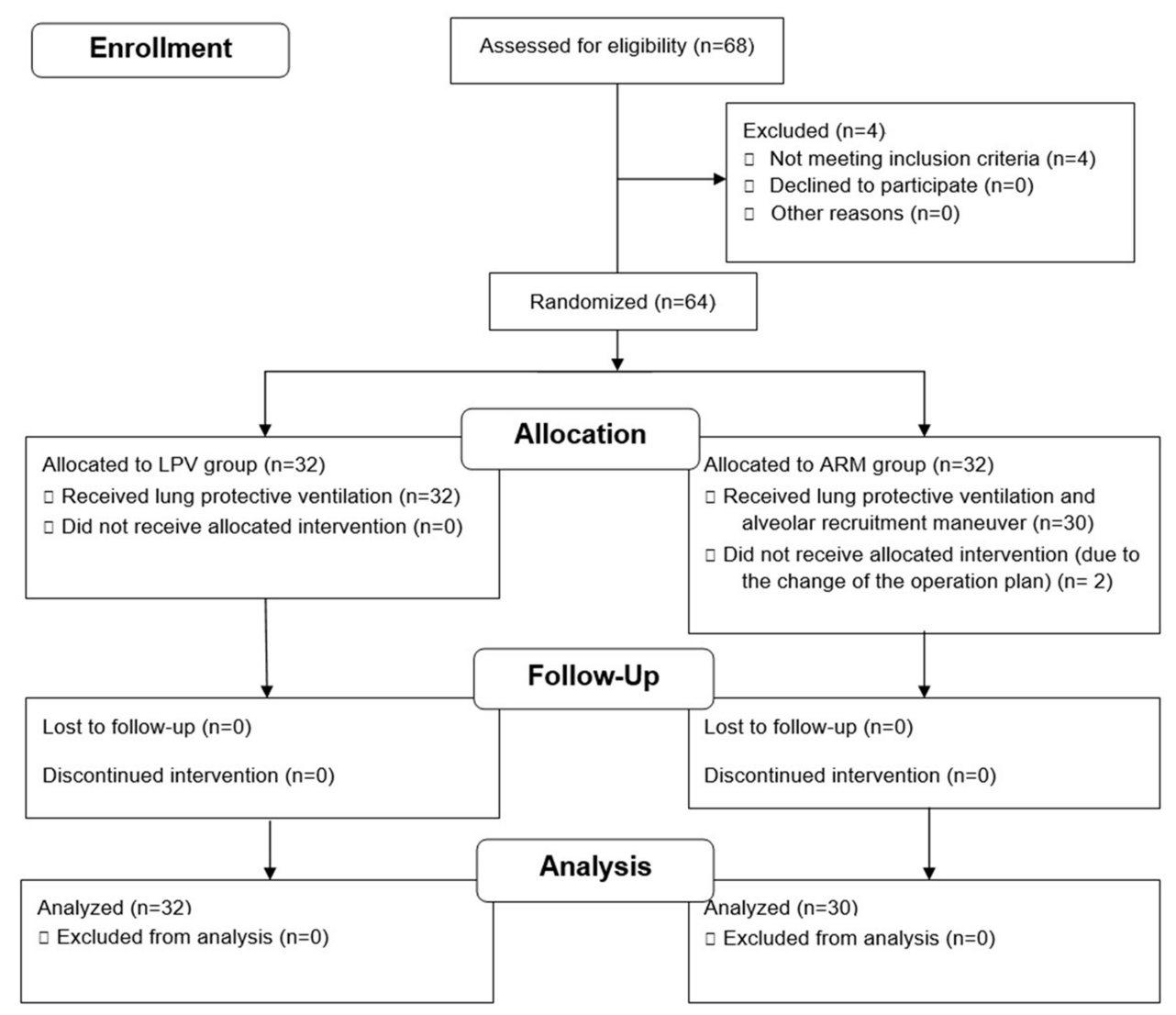

Figure I Patient allocation flow diagram.

and HR over time were not significant (group-by-time interaction $\mathrm{P}=0.736$ and 0.599 , respectively). However, the number of patients required vasopressor during surgery was significantly higher in the ARM group than in the LPV group (9 (30\%) vs 2 (6\%), $\mathrm{P}=0.014$, Table 2$)$.

\section{Postoperative Pulmonary Complications}

One patient in the LPV group had the symptom of dyspnea and showed postoperative desaturation and pulmonary edema on the chest X-ray. The detection of abnormalities on chest $\mathrm{X}$-ray such as atelectasis, pneumonia, or pulmonary edema was comparable between the groups (6 patients $(19 \%)$ in the LPV group vs 5 patients $(17 \%)$ in the ARM group, $\mathrm{P}=0.692)$. The number of patients who needed admission to the intensive care unit was comparable between the groups (Table 3).

\section{Discussion}

This study suggests that the additional use of an ARM during LPV may not significantly improve postoperative respiratory outcomes or intraoperative oxygenation compared to LPV alone in elderly patients undergoing laparoscopy in the Trendelenburg position. In addition, the ARM may cause a significant deterioration in hemodynamic parameters during the surgery.

Nearly $100 \%$ of patients experience atelectasis during general anesthesia; this could contribute to postoperative pulmonary morbidity rates. ${ }^{14,15}$ Decreases in lung compliance and functional residual capacity, as well as a high concentration of inspired oxygen, contribute to anesthesiainduced atelectasis. ${ }^{14}$ A previous study of LPV reported that low tidal volume ventilation with low PEEP during laparoscopy could reduce the incidence of PPCs as compared to conventional high tidal volume ventilation with an ARM. ${ }^{13}$ Another clinical study reported that the postoperative radiological atelectasis score after robot-assisted laparoscopic radical prostatectomy was significantly lower in patients maintained with a low tidal volume of $6 \mathrm{~mL} / \mathrm{kg}$ and a PEEP of $5 \mathrm{cmH}_{2} \mathrm{O}$ than in patients maintained with a high tidal volume of $10 \mathrm{~mL} / \mathrm{kg}$ and without PEEP. ${ }^{16}$ In a single-group study, the performance of an ARM followed by $5 \mathrm{cmH}_{2} \mathrm{O}$ PEEP after pneumoperitoneum was found to increase transpulmonary pressure and lead to improved alveolar recruitment and gas exchange during laparoscopy in the Trendelenburg position. ${ }^{17}$ In this study, 
Table I Patient Characteristics and Preoperative Pulmonary Variables

\begin{tabular}{|c|c|c|c|}
\hline & $\begin{array}{l}\text { LPV } \\
\text { Group } \\
(\mathbf{N}=\mathbf{3 2})\end{array}$ & $\begin{array}{l}\text { ARM } \\
\text { Group } \\
(\mathbf{N}=\mathbf{3 0})\end{array}$ & $P$ value \\
\hline Age, years & $76 \pm 7$ & $74 \pm 5$ & 0.125 \\
\hline Sex, M/F & $19 / 13$ & $15 / 15$ & 0.459 \\
\hline Weight, kg & $63 \pm 10$ & $60 \pm 13$ & 0.422 \\
\hline Height, cm & $160 \pm 9$ & $159 \pm 8$ & 0.752 \\
\hline \multicolumn{4}{|l|}{ Co-morbidities } \\
\hline Hypertension & $22(69 \%)$ & $21(70 \%)$ & 0.915 \\
\hline Diabetes mellitus & $7(22 \%)$ & $8(27 \%)$ & 0.660 \\
\hline \multicolumn{4}{|l|}{$\begin{array}{l}\text { Preoperative pulmonary } \\
\text { function test }\end{array}$} \\
\hline FVC, L & $2.9 \pm 0.8$ & $2.9 \pm 0.6$ & 0.775 \\
\hline $\mathrm{FEV}_{1}, \mathrm{~L}$ & $2.2 \pm 0.5$ & $2.2 \pm 0.5$ & 0.555 \\
\hline $\mathrm{FEV}_{\mathrm{I}} / \mathrm{FVC}, \%$ & $74.8 \pm 8.3$ & $75.6 \pm 7.8$ & 0.719 \\
\hline \multicolumn{4}{|l|}{ Arterial blood gas analysis } \\
\hline $\mathrm{pH}$ & $7.43 \pm 0.03$ & $7.44 \pm 0.03$ & 0.718 \\
\hline $\mathrm{PaCO}_{2}, \mathrm{mmHg}$ & $32.6 \pm 3.6$ & $32.8 \pm 4.9$ & 0.824 \\
\hline $\mathrm{PaO}_{2}, \mathrm{mmHg}$ & $92.7 \pm 17.0$ & $89.8 \pm 11.6$ & 0.434 \\
\hline
\end{tabular}

Notes: Values are presented as mean \pm SD or the number of patients (\%). Abbreviations: LPV group, patients who received lung protective ventilation; ARM group, patients who received both lung protective ventilation and an alveolar recruitment maneuver; FVC, forced vital capacity; FEVI, forced expiratory volume in the first second; $\mathrm{PaCO}_{2}$, arterial carbon dioxide tension; $\mathrm{PaO}_{2}$, arterial oxygen tension.

the level of PEEP was decided based on previous studies. ${ }^{10,18}$ The study by Meininger et $\mathrm{al}^{10}$ showed that the application of $5 \mathrm{cmH}_{2} \mathrm{O}$ of PEEP significantly improved arterial oxygenation without hemodynamic deterioration during prolonged pneumoperitoneum in elderly patients. In addition, in the meta-analysis of the effect of PEEP on postoperative pulmonary complication, the usual level of PEEP studied was from $5 \mathrm{cmH}_{2} \mathrm{O}$ to $10 \mathrm{cmH}_{2}$ O during anesthesia. ${ }^{18}$
The ARM reopens collapsed alveoli and induces the release of surfactant at an even distribution across the alveolar surface. ${ }^{11,14,15}$ There are several techniques in ARM method, such as sustained inflation followed by decremental PEEP, step-wise recruitment (incremental PEEP), airway pressure release ventilation, or highfrequency oscillation ventilation. A previous review reported that ARMs could improve intraoperative $\mathrm{PaO}_{2}$ and lung compliance regardless of the ARM method used; this review concluded that an ARM followed by PEEP after the induction of anesthesia might reduce PPCs. ${ }^{19}$ Meanwhile, a recent meta-analysis reported that ARM combining with LPV reduced the occurrence of PPCs and improved oxygenation in non-obese patients. ${ }^{8}$ Although they did not conclude the ideal strategy as the variable techniques of ARM, they suggested that sustained inflation might be better than step-wise recruitment on the development of PPC. ${ }^{8}$

We applied ARM immediately before and after pneumoperitoneum based on previous studies. ${ }^{20,21}$ A previous clinical study that examined the effect of preemptive ARM only before pneumoperitoneum reported that preemptive ARM improved arterial oxygenation and $\mathrm{AaDO}_{2}$ during the laparoscopic hysterectomy. ${ }^{20}$ Also, in the thoracic surgery, preemptive ARM before one lung ventilation effectively improves arterial oxygenation during the surgery. ${ }^{21}$ However, in this study, performing an ARM during LPV did not improve intraoperative oxygenation profiles and respiratory mechanics in elderly patients as compared to LPV alone. These results were consistent with those of Choi et $\mathrm{al}^{22}{ }^{22}$ who found that a single ARM before the induction of pneumoperitoneum did not improve intraoperative respiratory mechanics and oxygenation during robotic-assisted radical prostatectomy in elderly patients. There are a few possible explanations for the decreased

Table 2 Intraoperative Data

\begin{tabular}{|c|c|c|c|}
\hline & $\begin{array}{l}\text { LPV Group } \\
(\mathrm{N}=32)\end{array}$ & $\begin{array}{l}\text { ARM Group } \\
(N=30)\end{array}$ & $P$ value \\
\hline Operation time, min & $140 \pm 38$ & $147 \pm 54$ & 0.594 \\
\hline Anesthesia time, $\min$ & $177 \pm 42$ & $183 \pm 58$ & 0.627 \\
\hline Pneumoperitoneum time, min & $99 \pm 33$ & $105 \pm 48$ & 0.560 \\
\hline Number of patients required vasopressor during the surgery & $2(6 \%)$ & $9(30 \%)$ & 0.014 \\
\hline Phenylephrine (n) & $2(6 \%)$ & $8(27 \%)$ & \\
\hline Ephedrine ( $\mathrm{n}$ ) & $0(0 \%)$ & $2(7 \%)$ & \\
\hline
\end{tabular}

Note: Values are presented as mean \pm SD.

Abbreviations: LPV group, patients who received lung protective ventilation; ARM group, patients who received both lung protective ventilation and an alveolar recruitment maneuver. 

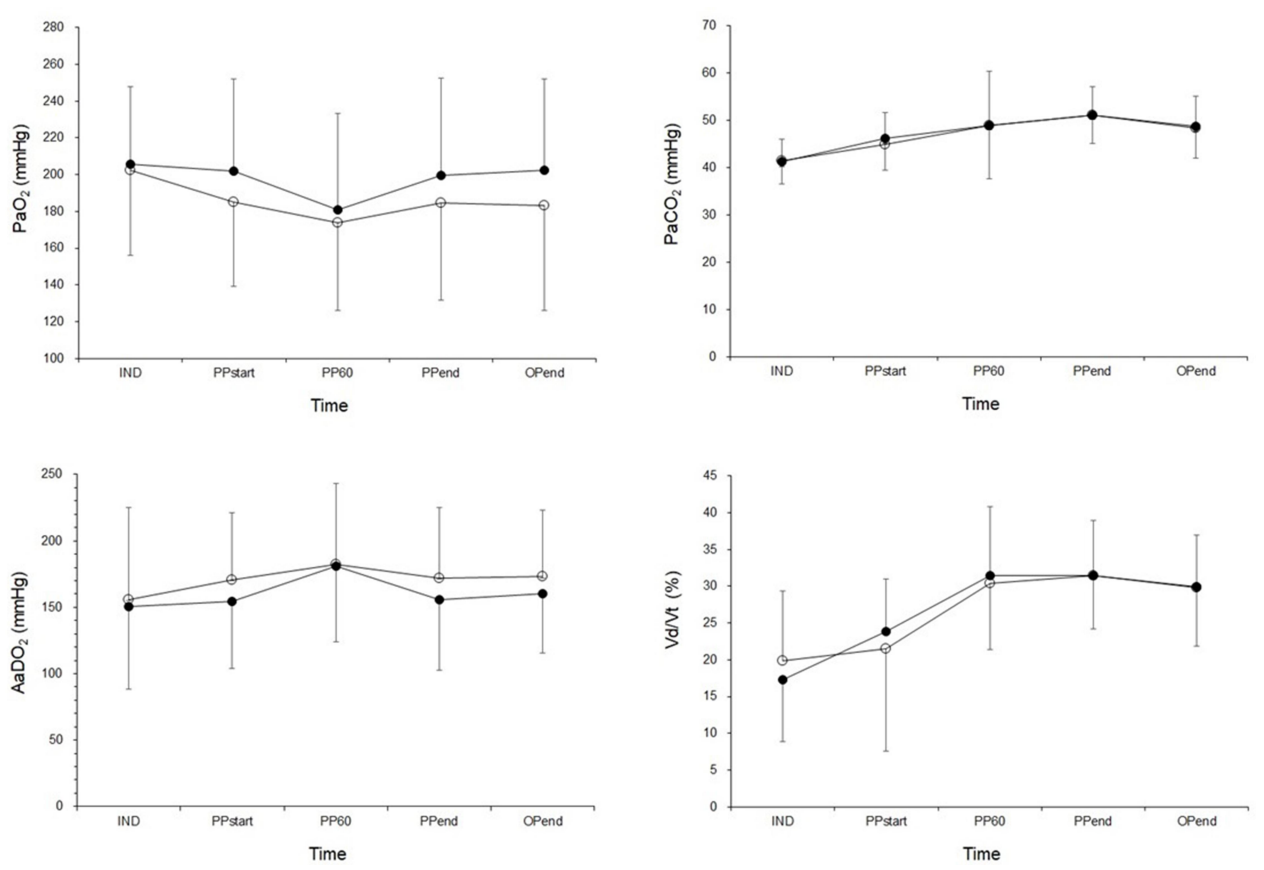

Figure 2 The changes in arterial oxygen tension $\left(\mathrm{PaO}_{2}\right.$, left upper), arterial carbon dioxide tension $\left(\mathrm{PaCO}_{2}\right.$, right upper), alveolar to arterial tension difference $(\mathrm{AaDO}$, left lower), and alveolar dead space fraction $\left(\mathrm{Vd} / \mathrm{Vt}\right.$, right lower) during the surgery. There were no significant differences between the groups in the changes in $\mathrm{PaO}_{2}, \mathrm{PaCO}_{2}$, $\mathrm{AaDO}_{2}$, and $\mathrm{Vd} / \mathrm{Vt}$ over time (group-by-time interaction $\mathrm{P}=0.615,0.818,0.624$, and 0.440 , respectively). Error bars represent standard deviation.

Abbreviations LPV group (unfilled circle, $\circ$ ), patients who received lung protective ventilation; ARM group (filled circle, $\bullet$ ), patients who received both lung protective ventilation and an alveolar recruitment maneuver; IND, 10 min after anesthesia induction; PPstart and PP60, I min and 60 min after the induction of pneumoperitoneum, respectively; PPend, the end of pneumoperitoneum; OPend, the end of surgery.
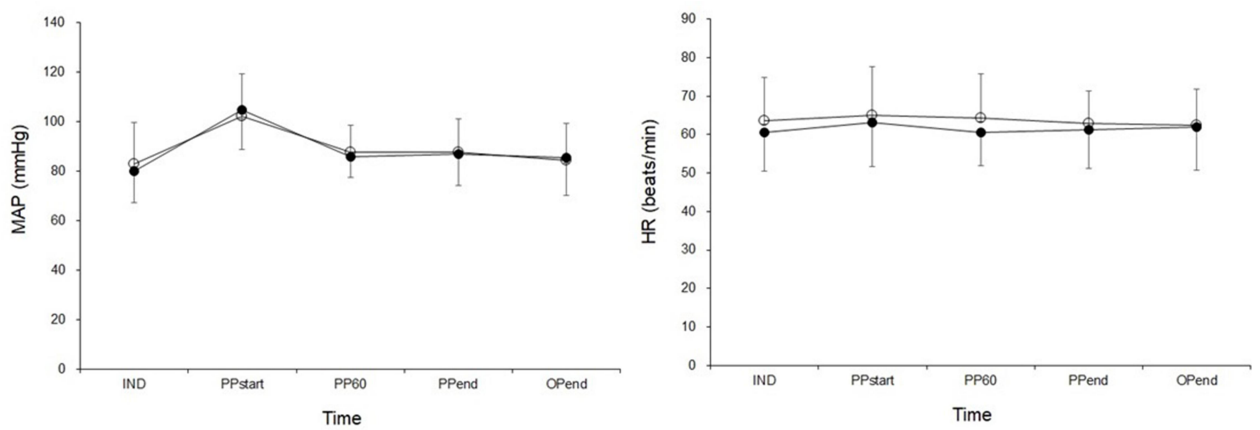

Figure 3 The changes in mean arterial pressure (MAP, left) and heart rate (HR, right) during the surgery. The differences between the groups in the changes in MAP and HR over time were not significant (group-by-time interaction $P=0.736$ and 0.599 , respectively). Error bars represent standard deviation.

Abbreviations: LPV group (unfilled circle, $\circ$ ), patients who received lung protective ventilation; ARM group (filled circle, $\bullet$ ), patients who received both lung protective ventilation and an alveolar recruitment maneuver; IND, 10 min after anesthesia induction; PPstart and PP60, I min and 60 min after the induction of pneumoperitoneum, respectively; PPend, the end of pneumoperitoneum; OPend, the end of surgery.

effect of ARMs in elderly patients. The first explanation is that, with aging, the loss of elastic recoil associated with the reduction in power of expiratory muscles can lead to alveolar hyperinflation and faster re-collapse of alveoli recruited by the ARM. This means that the effect of ARMs in elderly patients can be diminished. ${ }^{22}$ Furthermore, the loss of elastic recoil leads to an increase in residual volume and a decrease in vital capacity. ${ }^{23}$ In addition, a previous animal study suggested that protein deficiency, which can develop in old age, might lead to the degradation of surfactant and therefore impair lung function. ${ }^{24}$ In another animal study, decreased phospholipid content of surfactant was noticed with age; this might be caused by age-related pulmonary changes. ${ }^{25}$ Thus, surfactant protein deficiency or a decrease in phospholipid content may impair lung function in old age, which could limit the effect of the ARM in this study. There are several options for ARM. We only applied ARM before and after 
Table 3 Pulmonary Complications Within the First Two Days Postoperatively

\begin{tabular}{|l|l|l|l|}
\hline & $\begin{array}{l}\text { LPV } \\
\text { Group } \\
\text { (N = } \\
\mathbf{3 2 )}\end{array}$ & $\begin{array}{l}\text { ARM } \\
\text { Group } \\
\mathbf{( N = 3 0 )}\end{array}$ & P value \\
\hline $\begin{array}{l}\text { Desaturation event, No (\%) } \\
\text { Abnormal postoperative chest }\end{array}$ & $\begin{array}{l}\text { I (3\%) } \\
\text { X-ray, No (\%) }\end{array}$ & $0(0 \%)$ & 0.329 \\
Atelectasis & $5(17 \%)$ & 0.692 \\
Pneumonia & $5(16 \%)$ & $3(10 \%)$ & \\
Pulmonary edema & $0(0 \%)$ & I (3\%) & \\
ICU admission, No (\%) & I (3\%) & I (3\%) & \\
\hline
\end{tabular}

Abbreviations: LPV group, patients who received lung protective ventilation; ARM group, patients who received both lung protective ventilation and an alveolar recruitment maneuver; Desaturation event, $\mathrm{SpO}_{2}<90 \%$; ICU admission, admission to the intensive care unit after surgery.

pneumoperitoneum, but if we applied it with other options, such as hourly or every $30 \mathrm{~min}$ applying of $\mathrm{ARM},{ }^{26}$ we could have a more favorable effect on PPC or arterial oxygenation in elderly patients. Thus, further studies might be needed to find the ideal moments to re-open the de-recruited lungs.

In contrast to an earlier study of elderly patients undergoing laparoscopy, ${ }^{22}$ this study found that the ARM did not reduce the rate of PPCs. This discrepancy may result from differences in the age of enrolled patients and in anesthetic protocols. As mentioned earlier, age is a major risk factor for PPCs, and the average patient age in this study was about 10 years older than in the previous study. ${ }^{22}$ The anesthesia method can also affect postoperative pulmonary function and complications, and it is important to note that propofol was used in the previous study $^{22}$ while sevoflurane was used in this study. It has been found that the postoperative decrease in forced vital capacity is greater after intravenous anesthesia with propofol than after balanced anesthesia with sevoflurane in patients undergoing surgery in the prone position. ${ }^{27}$ In addition, another study found that in comparison to propofol anesthesia, sevoflurane anesthesia for lung resection surgery was associated with a reduced incidence of PPCs. This reduction was linked to the attenuation of systemic and pulmonary inflammatory responses. ${ }^{28}$

The increased intrathoracic pressure induced by ARMs significantly reduces venous return, decreases right ventricular filling, and consequently decreases stroke volume. ${ }^{29}$ In various lung injury models including pneumonia, oleic acid injury, and ventilator-induced lung injury, ARM has been shown to profoundly decrease cardiac output. ${ }^{30}$ Furthermore, restoration of cardiac output after ARMs in that study took 5-15 minutes. In addition, the increase in intra-abdominal pressure induced by the pneumoperitoneum itself compresses the inferior vena cava and reduces venous return. ${ }^{31}$ In the ARDS patients, a stepwise recruitment maneuver was preferred over sustained inflation because of the benefit of less hemodynamic compromise. ${ }^{32}$ Although we applied a stepwise ARM considering the hemodynamic vulnerabilities in old age, vasopressor use was significantly higher in the ARM group than in the LPV group in our study. It seems that the negative hemodynamic effects of the ARM were enhanced by old age and pneumoperitoneum in this study.

There are some limitations in the present study that warrant consideration. First, we excluded patients with uncontrolled obstructive respiratory disease, active inflammatory lung disease, or cerebrovascular disease. Considering the high frequency of these morbidities in the elderly population, our results cannot be generalized to all elderly patients. Second, we assessed PPCs only in the first 48 hours of the postoperative period. The European Perioperative Clinical Outcome (EPCO) definitions and other published definitions for PPCs also include clinical symptoms and laboratory findings, and do not limit the time period of assessment. ${ }^{33}$ Though we studied the effectiveness of an ARM in reducing atelectasis up to 2 days postoperatively, as this is the time period in which most cases of atelectasis occur, we did not assess PPCs that occurred thereafter. Further studies conducted in a larger population over a longer time period may be needed to obtain more definitive results. Third, we only recorded postoperative desaturation via pulse oximeter in the patients with dyspnea in the general ward. However, $\mathrm{SpO}_{2}$ might not reliably predict the equivalent change in arterial oxygenation in critically ill patients, ${ }^{34}$ and dyspnea and desaturation are not always consistent in elderly people. ${ }^{35}$ In this study, because the definition of PPCs does not include the sign of dyspnea and all patients had chest X-rays at 1st and 2nd postoperative day regardless of symptoms, no patient may be missing from the data of PPCs. Fourth, although we calculated sample size based on a previous report, ${ }^{13}$ our calculation may be short for the detection of severe complications, because this previous study did not involve elderly patients. We may have overlooked the fact that the risk of PPC doubles from 60 to 69 years and triples from 70 to 79 years. ${ }^{36}$ 


\section{Conclusion}

In conclusion, performing an ARM during LPV may not significantly improve respiratory parameters or postoperative respiratory outcomes compared to LPV alone in elderly patients undergoing laparoscopy in the Trendelenburg position. In addition, since the ARM could cause significant deterioration in hemodynamic parameters, applying ARM to elderly patients should be carefully considered.

\section{Data Sharing Statement}

The data used to support the findings of this study are available from the corresponding author upon request.

\section{Author Contributions}

All authors made a significant contribution to the work reported, whether that is in the conception, study design, execution, acquisition of data, analysis and interpretation, or in all these areas; took part in drafting, revising or critically reviewing the article; gave final approval of the version to be published; have agreed on the journal to which the article has been submitted; and agree to be accountable for all aspects of the work.

\section{Disclosure}

The authors declare no conflicts of interest in this work.

\section{References}

1. Weber DM. Laparoscopic surgery: an excellent approach in elderly patients. Arch Surg. 2003;138(10):1083-1088. doi:10.1001/ archsurg.138.10.1083

2. Sprung J, Gajic O, Warner DO. Review article: age related alterations in respiratory function - anesthetic considerations. Can J Anaesth. 2006;53(12):1244-1257. doi:10.1007/BF03021586

3. Shander A, Fleisher LA, Barie PS, Bigatello LM, Sladen RN, Watson CB. Clinical and economic burden of postoperative pulmonary complications: subject safety summit on definition, risk-reducing interventions, and preventive strategies. Crit Care Med. 2011;39 (9):2163-2172. doi:10.1097/CCM.0b013e31821f0522

4. Zaugg M, Lucchinetti E. Respiratory function in the elderly. Anesthesiol Clin North Am. 2000;18(1):47-58. doi:10.1016/s08898537(05)70148-6

5. Jo YY, Kim JY, Chang YJ, Lee S, Kwak HJ. The effect of equal ratio ventilation on oxygenation, respiratory mechanics, and cerebral perfusion pressure during laparoscopy in the trendelenburg position. Surg Laparosc Endosc Percutan Tech. 2016;26(3):221-225. doi:10.1097/ SLE.0000000000000276

6. Oikkonen M, Tallgren M. Changes in respiratory compliance at laparoscopy: measurements using side stream spirometry. Can $J$ Anaesth. 1995;42(6):495-497. doi:10.1007/BF03011687

7. Amato MB, Barbas CS, Medeiros DM, et al. Effect of a protective-ventilation strategy on mortality in the acute respiratory distress syndrome. $N$ Engl $J$ Med. 1998;338(6):347-354. doi:10.1056/NEJM199802053380602
8. Cui Y, Cao R, Li G, Gong T, Ou Y, Huang J. The effect of lung recruitment maneuvers on post-operative pulmonary complications for patients undergoing general anesthesia: a meta-analysis. PLoS One. 2019;14(5):e0217405. doi:10.1371/journal.pone.0217405

9. Reinius H, Jonsson L, Gustafsson S, et al. Prevention of atelectasis in morbidly obese patients during general anesthesia and paralysis: a computerized tomography study. Anesthesiology. 2009;111 (5):979-987. doi:10.1097/ALN.0b013e3181b87edb

10. Meininger D, Byhahn C, Mierdl S, Westphal K, Zwissler B. Positive end-expiratory pressure improves arterial oxygenation during prolonged pneumoperitoneum. Acta Anaesthesiol Scand. 2005;49 (6):778-783. doi:10.1111/j.1399-6576.2005.00713.x

11. Dietl P, Frick M, Mair N, Bertocchi C, Haller T. Pulmonary consequences of a deep breath revisited. Biol Neonate. 2004;85 (4):299-304. doi:10.1159/000078176

12. Canet J, Gallart L, Gomar C, et al. ARISCAT group. Prediction of postoperative pulmonary complications in a population-based surgical cohort. Anesthesiology. 2010;113(6):1338-1350. doi:10.1097/ ALN.0b013e3181fc6e0a

13. Park SJ, Kim BG, Oh AH, Han SH, Han HS, Ryu JH. Effects of intraoperative protective lung ventilation on postoperative pulmonary complications in patients with laparoscopic surgery: prospective, randomized and controlled trial. Surg Endosc. 2016;30 (10):4598-4606. doi:10.1007/s00464-016-4797-x

14. Hedenstierna G, Edmark L. Mechanisms of atelectasis in the perioperative period. Best Pract Res Clin Anaesthesiol. 2010;24 (2):157-169. doi:10.1016/j.bpa.2009.12.002

15. Güldner A, Kiss T, Serpa Neto A, et al. Intraoperative protective mechanical ventilation for prevention of postoperative pulmonary complications: a comprehensive review of the role of tidal volume, positive end-expiratory pressure, and lung recruitment maneuvers. Anesthesiology. 2015;123(3):692-713. doi:10.1097/ ALN.0000000000000754

16. Haliloglu M, Bilgili B, Ozdemir M, Umuroglu T, Bakan N. Low tidal volume positive end-expiratory pressure versus high tidal volume zero-positive end-expiratory pressure and postoperative pulmonary functions in robot-assisted laparoscopic radical prostatectomy. Med Princ Pract. 2017;26(6):573-578. doi:10.1159/000484693

17. Cinnella G, Grasso S, Spadaro S, et al. Effects of recruitment maneuver and positive end-expiratory pressure on respiratory mechanics and transpulmonary pressure during laparoscopic surgery. Anesthesiology. 2013;118(1):114-122. doi:10.1097/ ALN.0b013e3182746a10

18. Imberger G, McIlroy D, Pace NL, Wetterslev J, Brok J, Møller AM. Positive end-expiratory pressure (PEEP) during anaesthesia for the prevention of mortality and postoperative pulmonary complications. Cochrane Database Syst Rev. 2010;8(9):CD007922. doi:10.1002/ 14651858.CD007922.pub2

19. Hartland BL, Newell TJ, Damico N. Alveolar recruitment maneuvers under general anesthesia: a systematic review of the literature. Respir Care. 2015;60(4):609-620. doi:10.4187/respcare.03488

20. Park HP, Hwang JW, Kim YB, et al. Effect of pre-emptive alveolar recruitment strategy before pneumoperitoneum on arterial oxygenation during laparoscopic hysterectomy. Anaesth Intensive Care. 2009;37(4):593-597. doi:10.1177/0310057X0903700419

21. Park SH, Jeon YT, Hwang JW, Do SH, Kim JH, Park HP. A preemptive alveolar recruitment strategy before one-lung ventilation improves arterial oxygenation in patients undergoing thoracic surgery: a prospective randomised study. Eur J Anaesthesiol. 2011;28 (4):298-302. doi:10.1097/EJA.0b013e3283436fdb

22. Choi ES, Oh AY, In CB, Ryu JH, Jeon YT, Kim HG. Effects of recruitment manoeuvre on perioperative pulmonary complications in patients undergoing robotic assisted radical prostatectomy: a randomised single-blinded trial. PLoS One. 2017;12(9):e0183311. doi:10.1371/journal.pone.0183311 
23. Oyarzún GM. Pulmonary function in aging. Rev Med Chil. 2009;137 (3):411-418. doi:/S0034-98872009000300014

24. Walski M, Pokorski M, Antosiewicz J, et al. Pulmonary surfactant: ultrastructural features and putative mechanisms of aging. $J$ Physiol Pharmacol. 2009;60 Suppl 5(Supp150):121-125.

25. Christmann U, Hite RD, Witonsky SG, et al. Influence of age on surfactant isolated from healthy horses maintained on pasture. $J$ Vet Intern Med. 2009;23(3):612-618. doi:10.1111/j.1939-1676.2009.0298.x

26. Neuschwander A, Futier E, Jaber S, et al. The effects of intraoperative lung protective ventilation with positive end-expiratory pressure on blood loss during hepatic resection surgery: a secondary analysis of data from a published randomised control trial (IMPROVE). Eur $J$ Anaesthesiol. 2016;33(4):292-298. doi:10.1097/EJA.0000000 000000390

27. Tiefenthaler W, Pehboeck D, Hammerle E, Kavakebi P, Benzer A. Lung function after total intravenous anaesthesia or balanced anaesthesia with sevoflurane. $B r \quad J$ Anaesth. 2011;106(2):272-276. doi:10.1093/bja/aeq321

28. de la Gala F, Piñeiro P, Reyes A, et al. Postoperative pulmonary complications, pulmonary and systemic inflammatory responses after lung resection surgery with prolonged one-lung ventilation. Randomized controlled trial comparing intravenous and inhalational anaesthesia. Br J Anaesth. 2017;119(4):655-663. doi:10.1093/bja/ aex230
29. Fessler HE, Brower RG, Wise RA, Permutt S. Effects of positive end-expiratory pressure on the gradient for venous return. Am Rev Respir Dis. 1991;143(1):19-24. doi:10.1164/ajrccm/143.1.19

30. Lim SC, Adams AB, Simonson DA, et al. Transient hemodynamic effects of recruitment maneuvers in three experimental models of acute lung injury. Crit Care Med. 2004;32(12):2378-2384. doi:10.1097/01.ccm.0000147444.58070.72

31. Srivastava A, Niranjan A. Secrets of safe laparoscopic surgery: anaesthetic and surgical considerations. J Minim Access Surg. 2010;6(4):91-94. doi:10.4103/0972-9941.72593

32. Hess DR. Recruitment maneuvers and PEEP titration. Respir Care. 2015;60(11):1688-1704. doi:10.4187/respcare.04409

33. Miskovic A, Lumb AB. Postoperative pulmonary complications. $\mathrm{Br}$ J Anaesth. 2017;118(3):317-334. doi:10.1093/bja/aex002

34. Perkins GD, McAuley DF, Giles S, Routledge H, Gao F. Do changes in pulse oximeter oxygen saturation predict equivalent changes in arterial oxygen saturation? Crit Care. 2003;7(4):R67-R71. doi:10.1186/cc2339

35. Hjalmarsen A, Hykkerud DL. Severe nocturnal hypoxaemia in geriatric inpatients. Age Ageing. 2008;37(5):526-529. doi:10.1093/ageing/afn110

36. Sieber FE, Barnett SR. Preventing postoperative complications in the elderly. Anesthesiol Clin. 2011;29(1):83-97. doi:10.1016/j. anclin.2010.11.011
Clinical Interventions in Aging

\section{Publish your work in this journal}

Clinical Interventions in Aging is an international, peer-reviewed journal focusing on evidence-based reports on the value or lack thereof of treatments intended to prevent or delay the onset of maladaptive correlates of aging in human beings. This journal is indexed on PubMed Central, MedLine, CAS, Scopus and the Elsevier

\section{Dovepress}

Bibliographic databases. The manuscript management system is completely online and includes a very quick and fair peer-review system, which is all easy to use. Visit http://www.dovepress.com/ testimonials.php to read real quotes from published authors. 